\title{
Openly Accessible Microfluidic Liquid Handlers for Automated High- Throughput Nanoliter Cell Culture
}

\author{
Ying Zhou, Yuhong Pang, and Yanyi Huang* \\ College of Engineering, and Biodynamic Optical Imaging Center (BIOPIC), Peking University, Beijing 100871, China
}

Supporting Information

ABSTRACT: Cell culture is typically performed in Petri dishes, with a few million cells growing together, or in microwell plates with thousands of cells in each compartment. When the throughput of each experiment, especially of screening based assays, is increased, even using microliter solution per well will cost a considerable amount of cells and reagents. We took a rational approach to reduce the volume of each cell culture chamber. We designed and fabricated a poly(dimethylsiloxane) based liquid pipet chip to deliver and transfer nanoliter $(50-500 \mathrm{~nL})$ samples and reagents with high accuracy and robustness. A few

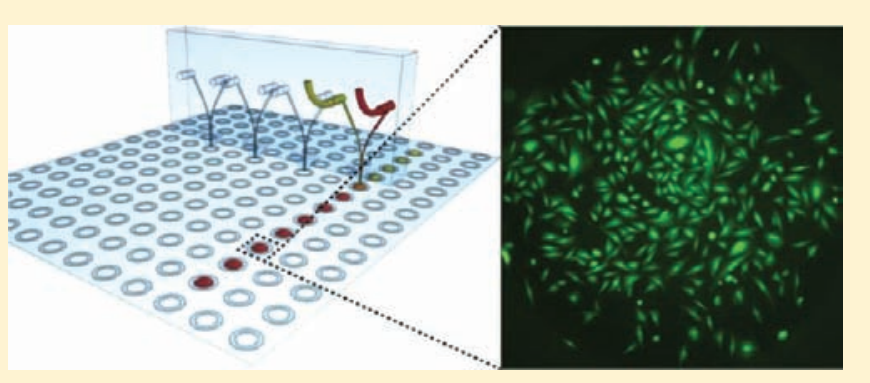
tens to a few hundreds of cells can be successfully seeded, transferred, passaged, transfected, and stimulated by drugs on a microwell chip using this pipet chip automatically. We have used this system to test the cell growth dynamically, observed the correlation between the culture conditions and cell viabilities, and quantitatively evaluated cell apoptosis induced by cis-diammineplatinum(II) dichloride (cisplatin). This system shows great potential to facilitate large-scale screening and high-throughput cell-array based bioassays with the volume of each individual cell colony at the nanoliter level.

$\mathrm{H}$ igh-throughput cellular assays are becoming necessary in many situations to decipher the complex network in chemical biology. ${ }^{1}$ They are also critical to drug screening ${ }^{2}$ and genomic profiling. ${ }^{3}$ These large-scale experiments would naturally prefer minute reaction volumes to reduce the waste and the total consumption of materials and reagents. ${ }^{4,5}$ Currently, high-density microwell plates, developed decades ago, are the popular platforms for high-throughput cell experiments. ${ }^{6}$ With the continuously increased throughput of each single experiment, the total volume consumption of well plates often becomes a bottleneck for cell assays. ${ }^{7}$ Besides, the relatively large bottom area is not suitable for single cell culture or microscopy observation.

Recently, two promising approaches, large-scale patterned cell arrays ${ }^{8,9}$ and highly integrated microfluidic devices, ${ }^{10}$ have been developed for cell culture and analyses on an even smaller scale. Many reported micropatterned cell arrays can achieve ultrahigh throughput for screening large libraries or rare events, but it is difficult to isolate one clone of cells from the other. ${ }^{11-13}$ There are also various microfluidic cell-culture chips that integrate customized microstructures inside of the channels to trap cells ${ }^{14-16}$ or create small chambers to generate an independent microenvironment. ${ }^{17}$ However, since the complexity and density of a single device increase enormously with the increase of integrated functional components such as valves, pumps, and necessary bypassing channels, it is still challenging to realize individual addressability. Moreover, the additional accessories for micropumps and valves, including pressurized gas supply, tubing, electronic circuits, and solenoid valves, are so cumbersome that the microfluidic chip-based cell culture has to be performed either in a customized incubation chamber ${ }^{17}$ or inside a conventional incubator with tubing all connected. Furthermore, the "world-to-chip" interface has been a problem for chiplike devices with many inlets for liquid introduction. ${ }^{18-20}$ It is always desirable to have a device that is openly accessible and can perform multistep experimental procedures such as complete functions of a liquid pipet including dispensation, removal, transfer, replacement, and mixing (typically due to aspiration-dispensation cycles), with great accuracy, robustness, and scalability. Previously reported technologies which handle cell arrays have successfully carried out positional cell seeding and release, ${ }^{21-23}$ and a digital microfluidic device also shows a promising future to culture, passage, and transfect a small amount of cells. ${ }^{24}$ However, without suitable robotic liquid handling systems, high-throughput manipulations in the cell culture and cell-based assays, such as medium change, addition and removal of stimulus, especially in a single reactor resolution, are still difficult to perform. ${ }^{25}$

In this paper, we present a dynamic nanoliter liquid handling system, which performs complete functions for cell culture. This system employs a microfluidic chip as the nanoliter liquid pipet chip for liquid handling and a corresponding microwellchip as the substrate for cell culture. This well-engineered system has surpassed our previously reported nanoliter dispenser, ${ }^{4}$ which can only perform one single liquid-handling function. To drive the liquid, we use the peristaltic pumps, instead of the compressed air as used in our previous report. To control the motion and positioning of the components, we use electronic translational stages.

Received: September 2, 2011

Accepted: February 9, 2012

Published: February 9, 2012 


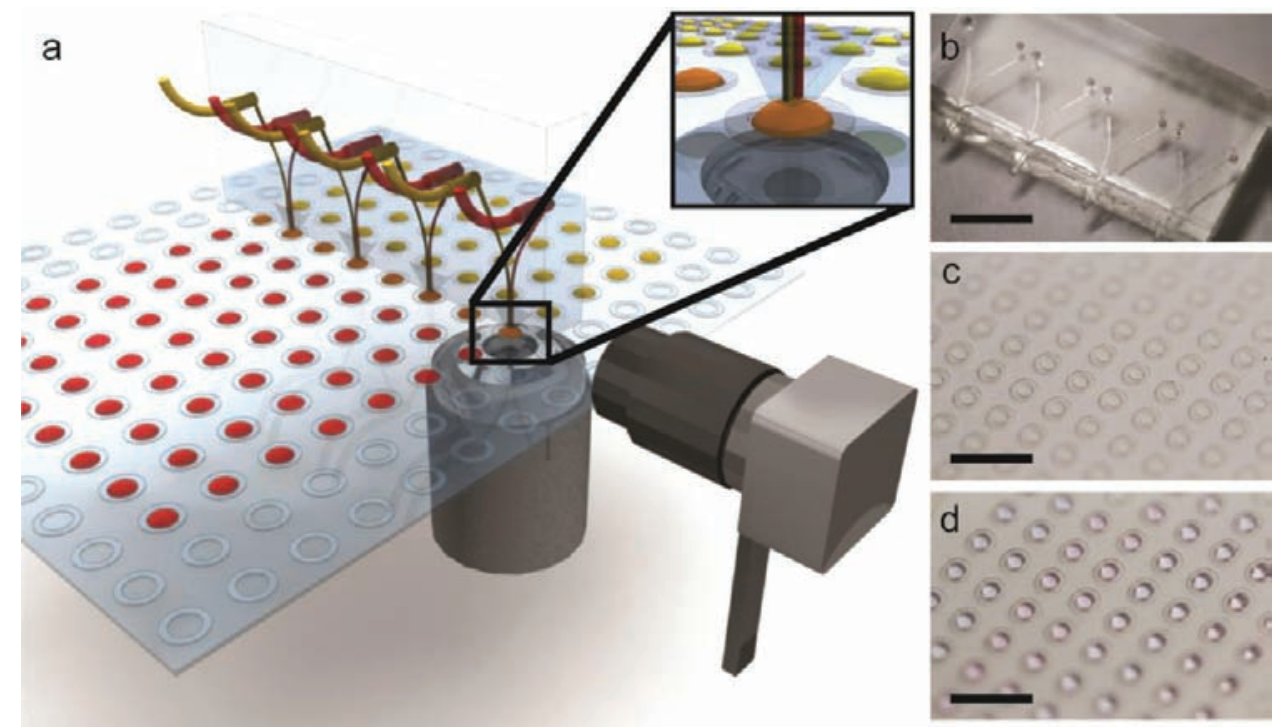

Figure 1. The microfluidic liquid handling system. (a) A microfluidic chip was aligned to the microwell chip horizontally and vertically using a microscope and a camera. Inset: a close view of the outlet of the microfluidic pipet chip. (b) A four-channel microfluidic liquid pipet chip. (c) Before and (d) after the microwell chip was filled with $\sim 350 \mathrm{~nL}$ of liquid sample in each well. Scale bars are $5 \mathrm{~mm}$.

The system can handle liquid from 50 to $500 \mathrm{~nL}$ in parallel, with a coefficient of variation $(\mathrm{CV})<8 \%$ at $150 \mathrm{~nL}$. We demonstrate uniform cell seeding in 96 microwells in a single run, with a volume of $\sim 350 \mathrm{~nL}$ for each well. All cells in these isolated wells can be maintained over $48 \mathrm{~h}$ with periodic medium changes every $8 \mathrm{~h}$. We also successfully perform cell passage and plasmid transfection of any given microwell with efficiency comparable to conventional practices. Furthermore, we observe cis-diammineplatinum(II) dichloride (cisplatin) induced cell apoptosis with three different dosages on a single microwell chip. We believe this method has great potential to be scaled up to much higher throughput and hence to be applied to various large-scale parallel cell assays.

\section{EXPERIMENTAL SECTION}

Automation and Imaging. As shown in Figure 1a, the microwell chip was mounted on an inverted microscope (Nikon TE2000-S, Japan) equipped with a motorized $X-Y$ stage (MLS203-E-OLY, Thorlabs), the microfluidic pipet chip was mounted on a $Z$ stage (TSA30-C, Zolix, Beijing, China) aligned on top of the $X-Y$ stage. Liquid flow was driven by two off-chip peristaltic pumps (BT100 1-F, Longer, Baoding, China) at speeds of 4.8 and $1.4 \mu \mathrm{L} / \mathrm{s}$ for dispensation and aspiration, respectively. The stages and peristaltic pumps were controlled by a home-built digital I/O controller with a computer. The $X-Y$ alignment between the microfluidic pipet chip and the microwells were done through the microscope objectives, while the $Z$ displacement was monitored through a photographic macrolens (MP-E, Canon, Japan) and a CCD camera (Marlin F-033B, Allied Vision Technologies, Germany). Phase contrast images and fluorescent images of microscale transfection were taken with a $10 \times$ objective and a CCD camera (IMG 2S, QHY, Beijing, China) on the microscope. Fluorescent images for conventional transfection and apoptosis detection were taken with a $10 \times$ objective and an EM CCD camera (iXon 897+, Andor Technology, U.K.) on an inverted microscope (Nikon TE2000-E, Japan). Videos of liquid handling were recorded by a CCD camera (WAT-221S, Watex, Japan) and digital cameras (EOS 5D Mark II, and
EOS 600D, Canon, Japan). Confocal microscopic images were taken with a confocal microscope (TCS SP5II, Leica Microsystems, Germany) for automatic cell counting.

Microfluidic Pipet Chip Fabrication. We fabricated microfluidic chips using the multilayer soft lithographic method. ${ }^{10,26}$ The mold for fluid layers were fabricated on a 3" silicon wafer using SU-8 1070 photoresist (Gersteltec, Switzerland) to get $100 \mu \mathrm{m}$ thick features. Similar to our previous design, ${ }^{4}$ the channel width was $200 \mu \mathrm{m}$ and tapered down to $100 \mu \mathrm{m}$ when getting close to the outlets. The chip was made from PDMS (RTV-615, GE Advanced Materials, Wilton, Connecticut). To fabricate the fluid layer, we treated the mold with trimethylchlorosilane (Sinopharm, Beijing, China) vapor for $5 \mathrm{~min}$, spin-coated PDMS (10:1 elastomer to cross-linker ratio, $700 \mathrm{rpm}, 60 \mathrm{~s}, \sim 180 \mu \mathrm{m})$ on the mold, baked the device at $80{ }^{\circ} \mathrm{C}$ for $12 \mathrm{~min}$, and then got the fluid layer pattern. To fabricate the scaffold layer, we poured PDMS (15:1 elastomer to cross-linker ratio, $\sim 3 \mathrm{~mm}$ ) on a blank 3 " silicon wafer pretreated with trimethylchlorosilane and baked the wafer with PDMS at $80^{\circ} \mathrm{C}$ for $15 \mathrm{~min}$. Then we peeled the scaffold layer off the wafer, cut it into two parts, and bonded them to the fluid layer, covering the whole device except the channel outlets region. Then we peeled the two scaffolds bonded with fluid layers and punched holes in one of them for channel inlets. To fabricate the isolating layer, we spin-coated PDMS (20:1 elastomer to cross-linker ratio, $2000 \mathrm{rpm}, 60 \mathrm{~s}$, $\sim 40 \mu \mathrm{m}$ ) onto a blank silicon wafer, baked at $80{ }^{\circ} \mathrm{C}$ for $12 \mathrm{~min}$. Sequentially, we bonded the hole-punched fluid layer with scaffold to the isolating layer by baking at $80^{\circ} \mathrm{C}$ for $30 \mathrm{~min}$ and then peeled off the bonded three-layer PDMS structure and punched other necessary inlets. We then bonded this piece with the other fluid layer with scaffold by the last baking at $80{ }^{\circ} \mathrm{C}$ overnight and then cut the nozzle part with scissors to get the final device.

Microwell Chip Fabrication. The microwell chip was fabricated on a $4.5 \mathrm{~cm} \times 6 \mathrm{~cm}$ coverslip (Matsunami Galss, Japan) by SU-8 1075 photoresist (Gersteltec, Switzerland) through conventional photolithography. Before putting into use, the coverslip was cleaned by hot piranha solution (a 3:1 
mixture of concentrated $\mathrm{H}_{2} \mathrm{SO}_{4}$ and $30 \% \mathrm{H}_{2} \mathrm{O}_{2}$ solution. Caution: Piranha solution is a vigorous oxidant and should be used with extreme caution!) for $10 \mathrm{~min}$, washed thoroughly with pure water, and baked at $90{ }^{\circ} \mathrm{C}$ for $3 \mathrm{~h}$. We then spincoated the photoresist on the coverslip (1200 rpm, $60 \mathrm{~s}$, $\sim 150 \mu \mathrm{m}$ ), waited for several hours, prebaked the photoresist (from 45 to $95{ }^{\circ} \mathrm{C}$, increase $10{ }^{\circ} \mathrm{C}$ per hour), and exposed it to $300 \mathrm{~mJ} / \mathrm{cm}^{2}$ of collimated UV light. After exposure, the photoresist was postbaked (from 45 to $95{ }^{\circ} \mathrm{C}$, increase $10{ }^{\circ} \mathrm{C}$ per hour) and developed. The microwell chip was finally baked at $150{ }^{\circ} \mathrm{C}$ for $3 \mathrm{~h}$.

Conventional Macroscale Cell Experiments. $\mathrm{CHO}$ and U2-OS cells were maintained in cell culture flasks and cultured in an incubator with $5 \% \mathrm{CO}_{2}$ at $37^{\circ} \mathrm{C}$. The culture medium for $\mathrm{CHO}$ and U2-OS cells were Dulbecco's modified Eagle's medium (DMEM, Invitrogen, Calsbad, CA) and McCoy's 5A Medium (GIBCO 16600, Invitrogen), respectively, both of which were supplemented with $10 \%(\mathrm{v} / \mathrm{v})$ fetal bovine serum (FBS, Invitrogen) and $1 \%$ penicillin-streptomycin (PS, Invitrogen).

CHO cells were cultured in 12-well plates (Costar 3513, Corning) for $48 \mathrm{~h}$ with medium replacement each $8 \mathrm{~h}$. The cells were maintained with 350,550 , and $750 \mu \mathrm{L}$ of medium in each well supplemented with $10 \%$ FBS.

For plasmid transfection, $\mathrm{CHO}$ cells were cultured in a 12well plate in $360 \mu \mathrm{L}$ of PS-free medium in each well to reach at least $90 \%$ confluence $\left(\sim 3 \times 10^{5}\right.$ cells per well). Prior to transfection, we prepared the transfection solution for one well by three steps: (1) mixed $1.2 \mu \mathrm{L}$ of lipofectamine 2000 (Invitrogen) and $59 \mu \mathrm{L}$ of Opti-MEM (Invitrogen), incubated for $5 \mathrm{~min}$ at $25^{\circ} \mathrm{C}$ and prepared $0.6 \mu \mathrm{g}$ of GFP plasmid DNA (GenePharma, Shanghai, China) in $59 \mu \mathrm{L}$ of Opti-MEM; (2) mixed these two solutions and incubated for $20 \mathrm{~min}$; (3) diluted the mixture by $240 \mu \mathrm{L}$ of PS-free DMEM supplemented with $10 \%$ FBS. After the solution was prepared, we replaced the medium by the transfection mix $(1.7 \mathrm{ng} / \mu \mathrm{L}$ plasmid and $360 \mu \mathrm{L}$ in total) and incubated the cells for $5 \mathrm{~h}$. Then we replaced the solution by fresh medium with PS and cultured the cells for another $20 \mathrm{~h}$ with medium replacement each $8 \mathrm{~h}$ before image acquisitions.

To induce apoptosis, U2-OS cells were cultured in a 96-well plate (655180, greiner bio-one, Germany) with $100 \mu \mathrm{L}$ of medium in each well to reach at least $90 \%$ confluence. A $50 \mathrm{mM}$ stock solution of cisplatin (Sigma) was prepared in DMSO. For the experimental groups, the old medium was replaced by fresh medium supplemented with 500,250 , or $80 \mu \mathrm{M}$ cisplatin at 8 and $16 \mathrm{~h}$ after cell seeding. For the control group, the old medium was replaced by fresh medium supplemented with $1 \%$ DMSO. After maintaining the cells in the drug-containing medium for $16 \mathrm{~h}$, we stained the cells with an annexin V-FITC cell apoptosis detection kit (KGA106, KeyGen BioTECH, Nanjing, China) by replacing the medium with $80 \%$ binding buffer supplemented with $13 \%$ Annexin V and $7 \%$ PI and then incubated for $10 \mathrm{~min}$ before imaging.

Cell Manipulation Using Nanoliter Microfluidic Liquid Handler. During the dispensation, the liquid was stored in 1.5 $\mathrm{mL}$ vials and pumped into microfluidic pipet chips by a multichannel peristaltic pump. For aspiration, we reversed the driving direction of the peristaltic pump. All the liquid manipulations were performed in a humidified environment to prevent evaporation of liquid in the microwells. Before cell seeding, we incubated the microwells with fibronectin (Fn, $150 \mu \mathrm{g} / \mathrm{mL}$ ) as the extracellular matrix protein for $1 \mathrm{~h}$ to improve cell attachment. Then we rinsed the microwell chip with PBS and dried it. When cells in the flask were harvested and rinsed in a fresh medium, we dispensed $\sim 350 \mathrm{~nL}$ of cell suspension to each well, yielding $\sim 500$ cells per well. We implemented a $2 \mathrm{~s}$ dwell time after dispensing cell suspension to one well to alleviate the cell's inertial movement. After liquid manipulation, the microwell chip containing cells was immediately moved into a humidified chamber (diameter $15 \mathrm{~cm}$ ) and then placed in a conventional $\mathrm{CO}_{2}$ incubator. ${ }^{27}$ For liquid change, eight change cycles were implemented with $45 \%$ liquid changed per cycle and $5 \mathrm{~s}$ interval between every four cycles if not specially mentioned. In all experiments, the volume of each well is kept the same after a medium change.

For a longtime cell culture, the medium was DMEM total medium supplemented with $10 \%$ FBS and $0.5 \%$ PS, and the time interval between each two medium changes was $8 \mathrm{~h}$ if not specially mentioned. For cell counting, we stained the cells at the 48 th $\mathrm{h}$ by replacing the medium with $10 \mu \mathrm{M}$ Hoechst 33342 (Dojindo, Japan) in DMEM and incubating for $20 \mathrm{~min}$. Cells were stained only at the end of the experiment to avoid the dye's potential affection to cell growth.

For GFP plasmid transfection, CHO cells were cultured in microwells in the PS-free medium for $12 \mathrm{~h}$ to reach at least $90 \%$ confluence. Each microwell contained $\sim 700$ cells. We used the same transfection mix prepared for the conventional methods to perform our chip-based transfection. We added $350 \mathrm{~nL}$ of transfection mix into each microwell. To induce apoptosis, U2OS cells were cultured in microwells for $12 \mathrm{~h}$. The remaining procedures for both experiments were the same as the corresponding macroscale experiments except that all the liquid manipulations were performed by the liquid handler.

Cell Counting. Cell numbers were counted to evaluate the proliferation rate, transfection efficiency, as well as the apoptosis rate. Cell numbers were manually counted in the bright field images using Image $\mathrm{J}^{28}$ with the "cell counter" plugin. For the fluorescent images, we counted the cells with homedeveloped image processing scripts in Matlab (Mathworks, Natick, MA). Automatic cell counting was as accurate as manual counting, as shown in Figure $S 1$ in the Supporting Information.

\section{RESULTS AND DISCUSSION}

Characterization of the Liquid Handler. For easier observation of the manipulating process of liquid at the nanoliter range, we built our system on top of an inverted microscope (Figure 1a). An $X-Y$ translational stage was used to control the receiving microwell chip to align to the vertically placed microfluidic pipet chip (Figure $1 \mathrm{~b}$ ), which was mounted on a $Z$-axis translational stage for accurately adjusting the distance between the pipet chip and the microwell chip. This chip-to-chip configuration, which makes arrays of liquid droplets openly accessible, is similar to commercially available liquid handling robots using multiple pipet tips (or capillary needles) with multiwell plates for microliter operations. Microfluidic devices with open outlets, such as spotters, ${ }^{29,30}$ dispensers, ${ }^{4}$ chemistrodes, ${ }^{31,32}$ and circulating liquid tip pipet, ${ }^{33}$ have been developed to carry out bioassays in confined volumes. In the current system, we further extend the functions of open-channel microfluidic chips by integrating four liquid manipulation modes: dispensation, removal, replacement, and aspiration-dispensation. Combining these four modes, complete manipulations for cell culture, including cell seeding, 
medium change, cell passage, transfection, and drug stimulation, can be performed at the nanoliter range.

The microwell chip consists of arrays of open chambers to hold liquid, as shown in Figure 1c. We typically pattern 96 $(12 \times 8)$ isolated microwells on a $4.5 \mathrm{~cm} \times 6 \mathrm{~cm}$ glass substrate for cell culture and optical observation. The wall of the wells is hydrophobic, made from SU-8 photoresist, while the bottom is hydrophilic glass substrate. Each well's inner diameter is $1.12 \mathrm{~mm}$, offering the maximum volume of $\sim 500 \mathrm{~nL}$ with a convex surface due to surface tension (Figure 1d).

The design of the pipet chip has been evolved from a format similar to the original dispenser ${ }^{4}$ to an optimized form with extended nozzles (Figure 1a,b). First, we employed a microfluidic pipet chip with one channel corresponding to one microwell, as shown in Figure 2a. Using a bidirectional

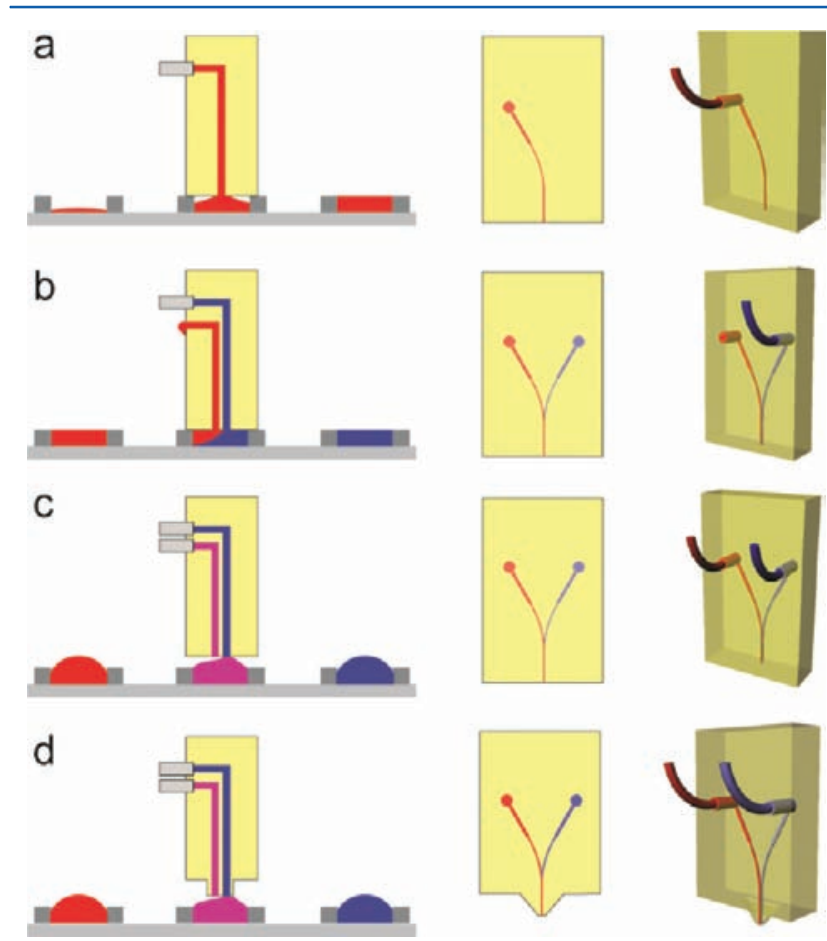

Figure 2. Four different versions of microfluidic chips we employed to perform liquid handling: (a) The first version had a flat bottom and one channel connected to a peristaltic pump. This chip is suitable for dispensation. (b) The second version had a flat bottom and two individual channels, one of which was connected to a peristaltic pump, and when injecting new liquid, the old liquid would be pushed out of the well. (c) The third version also had two individual channels, connected to two different peristaltic pumps, one for dispensation and the other for aspiration. (d) The fourth version had a nozzle-shaped outlet for easier and more efficient liquid manipulation.

peristaltic pump for liquid driving, the chip was capable of liquid dispensation or aspiration. Cell suspension can be loaded into and sucked out of the microwells with this setup. However, this one-channel-one-well configuration is difficult to perform culture medium change efficiently since the new medium and the old medium have to share the same channel, and the pipet tip has no access to the bottom of the microwells for complete liquid aspiration. One solution to this problem is to have a pair of channels, one for delivery and the other for removal, to address each microwell. To save space, we aligned two channels together, as shown in Figure $2 \mathrm{~b}$. The thickness of the pipet chip is greater than the microwell's diameter. We gently sealed the microwells by covering the microwells with the end-facet of the elastic PDMS chip, and through this design the old medium inside of the microwells could be pushed out of one channel while the new replacement is driven into the microwell through the other channel by a peristaltic pump. There are two challenges associated with this approach. One is that the pipet chip and the microwell chip must be tightly sealed and the liquid surface must be lower than the well's wall. If not tightly sealed, the medium would leak through the gap between chips during liquid handling. The other challenge is that the intrinsic nature of the laminar flow will limit the efficiency of medium replacement in the microwells. To tackle this challenge, we used two peristaltic pumps to drive the liquid flow with opposite directions in the two channels, respectively (Figure $2 \mathrm{c}$ ). This improvement not only lowers the requirement for the plateaus flatness but also allows convex droplets.

To further improve the pipet part, we created a fine nozzle at the chip's end-facet embedded with two aligned channel outlets (Figure 2d). This nozzle allows the pipet to access the bottom of the microwells, so as to remove most of the liquid inside. This design is the most efficient way to perform pipetting, compared to the three former versions. The pipet chip contains five layers of PDMS: a stack of three thin layers, two fluid layers, and one isolating layer, are sandwiched between two $3 \mathrm{~mm}$ thick scaffold layers, making the connection with the peristaltic pump tubing stable (Figure la,b). In contrast to a previously reported circulating liquid tip pipet, ${ }^{33}$ which patterned multiple channels in a single fluid layer, we purposely placed two channels in different layers to reduce the fabrication difficulties. We found that if the two channels are placed adjacent to each other in the same layer, for the channel size we typically used $(100 \mu \mathrm{m} \times 100 \mu \mathrm{m})$, the smallest gap had to be at least $50 \mu \mathrm{m}$ to guarantee tight sealing. While placed in two different layers, the separation of two channels can be well adjusted through the thickness of the thin PDMS membrane in between, which can be made as thin as a few micrometers. This feature makes sure the pipet chip can be used for smaller microwells and that the two outlets are both close to the center of the microwells for reproducible pipetting.

To run the experiments in parallel, we fabricated a microfluidic pipet chip with four pairs of channels to fit the microwell chip with a $12 \times 8$ array. We set the pitch between channel outlet-pairs twice as much as that between microwells (Figure 1a). With this setup, a customized computer program can perform liquid handling efficiently, and each pipetting nozzle has to handle liquid for 24 different microwells in serial. We need to implement a cleaning step between two handling processes to prevent cross contamination. Nozzle cleaning can be performed by repeating aspiration-dispensation cycles many times using washing buffer. This step is critical for those experiments that screen the cell behavior under the different culture conditions. The main components of the system, the microfluidic chip and the microwell chip, are easy to fabricate, to operate, and to be scaled to higher throughput and 10 -fold smaller size.

Quantitative Liquid Handling. The pipet chip is aligned perpendicularly to the microwell chip for liquid manipulation. On the basis of the accuracy of our peristaltic pump and its controller, liquid can be manipulated in a quantitative manner with the resolution of $\sim 5 \mathrm{~nL}$.

Dispensation. Dispensation is a basic function of the liquid handler. It includes three steps: (1) move the pipet chip to the appropriate height above the top plateau of the microwells, (2) generate droplets through the peristaltic pump, and (3) raise 
the pipet chip and release the liquid from the pipet tips; the tips are moved to new locations for the next dispensation. The tipmicrowell gap is critical to secure good reproducibility and uniformity and to minimize the residue of the droplets on the outlet facet. The tip-microwell gap should be small enough to allow a droplet to touch the bottom but not too small that the tip would be immersed in the droplet. The immersion can be avoided by raising the pipet chip while generating droplets in step 2 . We typically set the gap within the range of $30-200 \mu \mathrm{m}$, depending on the size of the droplets. For cell dispensation, we added a $2 \mathrm{~s}$ dwell time after step 2 to make sure the cell's inertial movement stops and guarantee uniform cell density across the microwell chip. The dwell time was typically $0.5-3 \mathrm{~s}$, decided by the liquid injection speed. The droplet volume depends on the duty time and the velocity of the pump.

Removal. Removal of liquid is as much important as dispensation during a pipetting cycle. The procedure includes three steps: (1) move and align the pipettes toward the top of the droplets; (2) the peristaltic pump turns reversely to aspirate liquid and the pipet chip moves down simultaneously until the scheduled amount of liquid is removed; (3) the pipet chip moves up and gets ready for the next removal. During the whole process, the descending speed of the pipets must match the aspirating speed to ensure the tips just touch the liquid. If the aspiration speed is too slow, the tips will be immersed in the liquid and hence liquid is left on the facet surface.

Replacement. Replacement is to change the liquid in a well. It is essential to keep the cell reservoir hydrated all the time to reduce cell damage. Thus we made a strategy to partially replace the liquid during one cycle, which contains removal and dispensation steps. A complete liquid replacement can be realized after several cycles, as illustrated in Figure $3 \mathrm{a}$. The

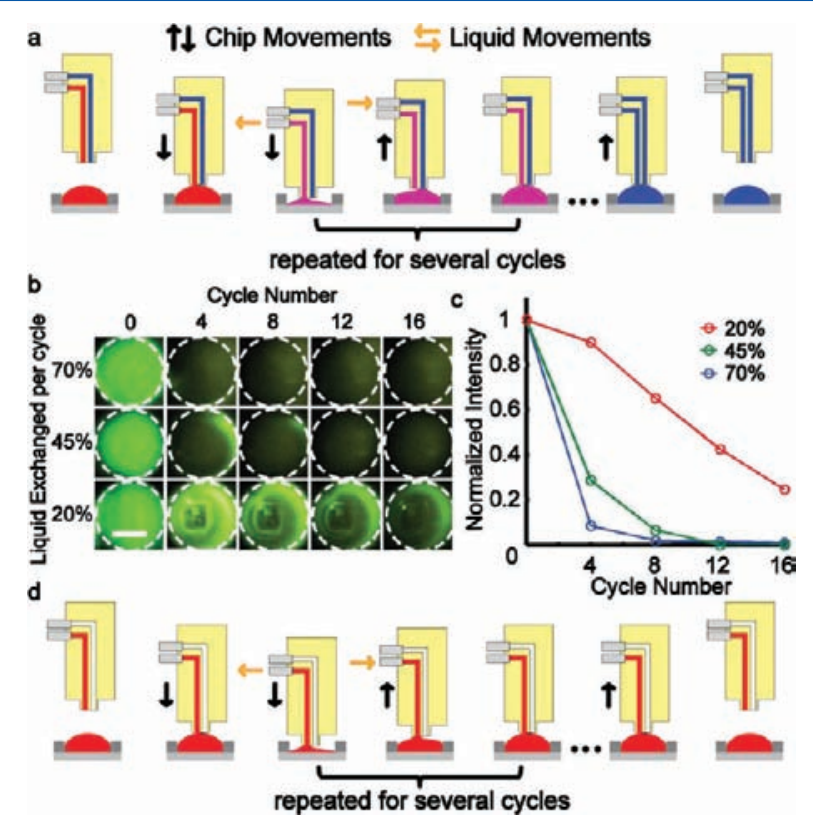

Figure 3. (a) Illustration of liquid replacement. Red solution is replaced by the blue solution after several "removal and dispensation" cycles. (b) Evaluation of efficiency of liquid replacement by changing fluorescein solution with PBS. Scale bar is $0.5 \mathrm{~mm}$. (c) Fluorescent intensity of the solution in the microwells is plotted as a function of the replacement cycle number. (d) Illustration of the "aspirationdispensation" process. The solution (red) is removed from and reinjected into the microwells for several times to facilitate mixing or to generate a hydrodynamic force. removal and dispensation are performed through separated microfluidic channels/outlets, respectively. We found that the effective efficiency of liquid replacement is highly dependent on three factors: the amount of liquid replaced per cycle, the cycle number, and the dwell time between cycles which determines the diffusion completeness in the well. We used fluorescence microscopic images to quantitatively evaluate the efficiency of liquid replacement by changing the fluorescein solution with phosphate buffered saline (PBS). We performed a series of tests through 16 removal-dispensation cycles, with $5 \mathrm{~s}$ dwell between every 4 cycles and for each cycle the liquid replacement was set at $70 \%, 45 \%$, or $20 \%$. The fluorescent microscopic images are shown in Figure $3 \mathrm{~b}$, and the quantitative analysis of these images is plotted in Figure 3c. The fluorescence intensity decreased to zero as the cycle number increased, indicating the completion of liquid replacement. As expected, the larger portion of liquid is changed per cycle, and fewer cycles are needed. For $70 \%$ and $45 \%$ liquid change per cycle, it took 8 and 12 cycles, whereas for $20 \%$ liquid change per cycle, it needed more than 16 cycles.

Aspiration-Dispensation. Aspiration-dispensation cycles are commonly used during liquid handling processes to facilitate solvation and mixing, to generate homogeneous microenvironments, and to enhance the biochemical reactions. Aspirationdispensation cycles also generate a hydrodynamic force without changing the liquid volume, thus, especially useful for cell detachment. The aspiration-dispensation cycle is similar to liquid replacement, except that in an aspiration-dispensation cycle the liquid flows in and out of the microwells through the same channel (Figure 3d), while during the liquid replacement two channels are used (Figure 3a). We typically aspirated $90 \%$ of the liquid in a microwell and then dispensed back and repeated for a few cycles to generate strong hydrodynamic force. It is critical to ensure that the amount of liquid aspirated and dispensed should be the same to prevent air bubbles.

Cell Manipulation. Cell Seeding. Uniform cell density across all microwells is critical for parallel screening. In most microfluidic cell culture systems, in which cells are typically put into closed chambers, it is challenging to make cells equally distributed into different chambers because the flow resistances are usually different between chambers when connected to different channels. One way to solve this problem is to perform a sequential loading procedure, which inevitably consumes more time when throughput is increased. ${ }^{17}$ Another approach is to use open systems, in which several methods, including wiping, ${ }^{34}$ vacuum-assist seeding, ${ }^{35}$ and washing away unattached cells after seeding, ${ }^{36}$ have been reported. Recently, inject printing is becoming a facile access for cell microarray generation at the single cell level. ${ }^{25,37-40}$ Our liquid handler has but not limited to the function of inject printing. We dispensed $350 \mathrm{~nL}$ cell suspension to 12 by 8 microwells, resulting in 400500 cells per well with a coefficient of variation $(\mathrm{CV})$ of $\sim 15 \%$ in 96 wells, which is acceptable for most cell-related assays. This uniformity is achieved mainly because of the liquid driven by the peristaltic pump is not sensitive to the difference of flow resistance between the channels. The uniformity can be guaranteed as long as the tygon tubings of the pumps have similar weariness. The cells attached to the surface within $1 \mathrm{~h}$ and exhibited a well-adhered morphology in 4-8 h, suggesting that no cell damage was caused during the dispensation. The population ratio between the suspended cells and the attached cells in microwells $(6.0 \pm 0.45 \%)$ was comparable to that of the cells conventionally cultured in the flask $(6.4 \pm 1.1 \%)$, as shown in 


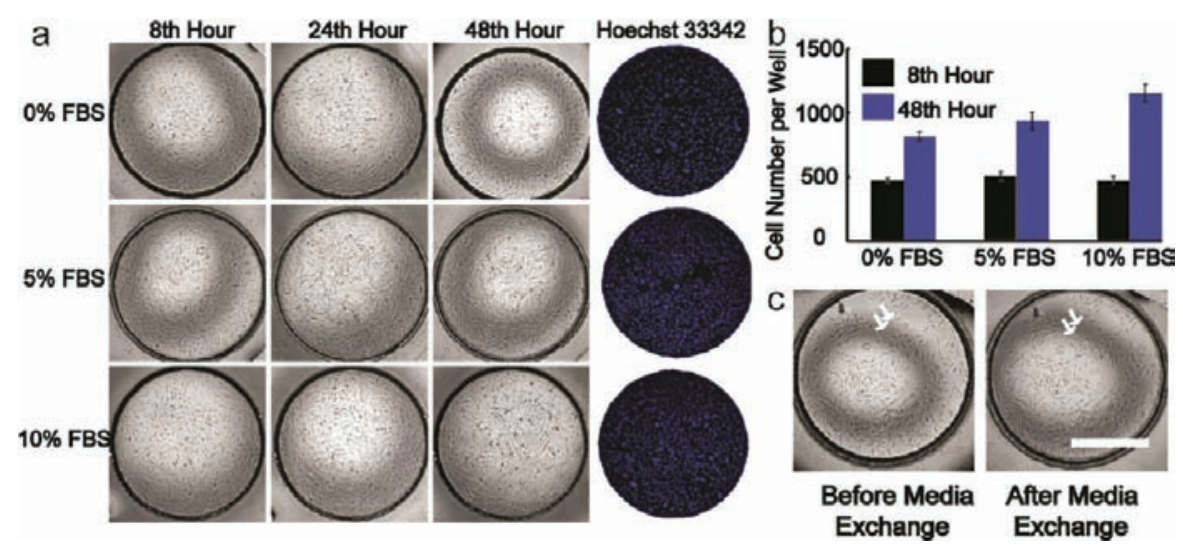

Figure 4. Demonstration of longtime cell culture using the liquid handling system. (a) Around 500 cells were seeded and cultured in each microwell in DMEM with $0 \%, 5 \%$, and 10\% FBS for $48 \mathrm{~h}$. The medium was changed for every $8 \mathrm{~h}$. Cells were labeled with Hoechst 33342 at the 48 th hour for cell counting. (b) Cell numbers at the 8th and the 48th hour were counted manually and through image processing. (c) Some dead cells and debris (indicated by arrows) were taken away during the medium change. Scale bar is $0.5 \mathrm{~mm}$.

Figure $S 2$ in the Supporting Information. The cell number ranging from 50 to more than 1000 is suitable for our microwell culture chip, as long as the cells are not too crowded in the wells.

Medium Change. Medium change is necessary for longtime cell culture. If the medium is changed completely during one cycle, it is easier to cause dehydration in the nanoliter cell reservoir than at the microliter scale. Our liquid handling system keeps cells hydrated all the time because of multiple cycles of partial replacement. To do it successfully, the amount of liquid replaced per cycle should be properly determined. Although it seems to be more efficient to increase the portion of liquid replacement per cycle, the portion must be limited. The adherent cells can handle the hydrodynamic force generated by liquid removal and dispensation. When we attempted to replace all the liquid in the well in one cycle, the nozzle had to be brought to the bottom of the well. In total, $98 \%$ of the liquid would be replaced if the distance between the nozzle and the bottom of the well was as close as $5 \mu \mathrm{m}$. However, cells next to the nozzle would be easily detached and flushed, probably because the nozzle touched the cells and mechanically scratched some away (Figure S3 in the Supporting Information).

We carefully investigated this issue by changing $70 \%, 45 \%$, and $20 \%$ of the liquid of a well during each cycle. The entire evaluation took $48 \mathrm{~h}$, with the medium changed every $8 \mathrm{~h}$ and eight replacement cycles per medium change (Figure S4 in the Supporting Information). The eight cycles were performed in two batches, with four continuous cycles per batch and $5 \mathrm{~s}$ dwell time between the two batches. The liquid replacement took away loosely attached cells and created a few blanks in the microwells. Cells left in the microwells showed normal morphology and would migrate to the blank regions during culture. Cells in all three groups exhibited regular proliferation. For $70 \%, 45 \%$, and $20 \%$ liquid replacement per cycle, respectively, the numbers of cells at the 48th hour were 2.4, 2.3, and 1.8 times of those at the 8th hour. Increasing liquid replacement of each cycle from $45 \%$ to $70 \%$, cell proliferations do not accelerate significantly, because both approaches replace more than $90 \%$ of the liquid after 8 cycles (Figure 3c). Besides, the cells stop proliferating after confluence. Cell proliferation is affected not only by the amount of fresh medium in each replacement but also by the frequency of medium change. Cells cultured with the medium changed every $8 \mathrm{~h}$ have sufficient nutriment and showed higher proliferation rate than those with longer time intervals (16 or $24 \mathrm{~h}$, see Figure S4 in the Supporting Information).
We then investigated the cells' response to different serum concentration in microwells. We replaced $45 \%$ liquid during each cycle, eight cycles per medium change, and one change every $8 \mathrm{~h}$. We seeded $\sim 500$ cells and cultured for $8 \mathrm{~h}$ in a medium supplemented with $10 \%$ fetal bovine serum (FBS). Then we replaced the medium and cultured the cells to the 48th hour with medium supplemented with $0 \%, 5 \%$, and $10 \%$ FBS, respectively. Figure 4a shows phase contrast microscopic pictures of cells cultured in microwells. Cells are well-attached and alive. From the 8 th hour to the 48th hour, the cell number was increased by a factor of $1.6,1.8$, and 2.3 when cultured in $0 \%, 5 \%$, and $10 \%$ FBS, respectively (Figure $4 \mathrm{~b}$ ). A high concentration FBS provides more growth factors, facilitating cells' proliferation. Comparing images before and after the medium change (Figure 4c), we observed that some dead cells and debris were taken away during liquid aspiration, without affecting the living cells.

To evaluate the performance of our nanoliter cell culture system, we performed the cell culture in 12-well plates as comparison. We found that the cells grew slightly faster with $750 \mu \mathrm{L}$ of culture medium per well than with $350 \mu \mathrm{L}$ per well, indicating that cell proliferation is not critically dependent on the medium volume (Figure S5 in the Supporting Information). The proliferation rate we achieved in the microwells is comparable to that from conventional culture, indicating the normal behavior of cells living in the nanoliter chambers.

Cell Passage. Passaging cells is necessary for longtime cell culture and cell lines maintenance. Combining the four liquid manipulation modes, we used our system to automatically harvest cells from four microwells, to transfer and reseed the cells into eight new microwells in parallel. The whole procedure is the same as the regular protocol for cell culture in Petri dishes, including PBS wash, trypsin incubation, trypsin neutralization, and cell transfer. We first replaced the culture medium with PBS and then replaced PBS with trypsin. The cell attachment was firm enough that the hydrodynamic force generated by the liquid flow could not detach cells without trypsin treatment. After incubation in $37^{\circ} \mathrm{C}$ for $2 \mathrm{~min}$, we removed $80 \%$ liquid from the microwells and replaced with the same amount of medium supplemented with $10 \%$ FBS. We usually repeated this replacement process one more time to ensure that trypsin was completely removed and neutralized. A small amount of overtrypsinized cells were taken away through this procedure. After neutralization, we detached cells from the bottom surface inside 


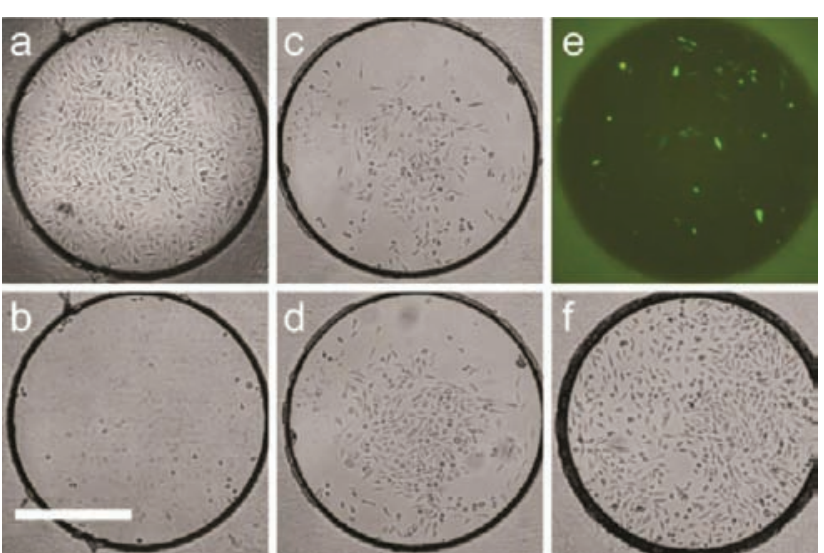

Figure 5. Demonstration of cell passage and transfection using the liquid handling system. (a) Cells in a well reached confluence after $12 \mathrm{~h}$ culturing. (b) Cells in the well were trypsinized, detached, and transferred to two other wells, leaving few cells in the original well. Cells adhered to the new well and proliferated for $8 \mathrm{~h}$ (c) and $22 \mathrm{~h}$ (d) after the passage. (e) Fluorescent and (f) bright field images show that $13 \%$ cells in the well expressed GFP $20 \mathrm{~h}$ after the transfection of GFP plasmid DNA. Scale bar is $0.5 \mathrm{~mm}$.

the microwells by aspirating and dispensing $90 \%$ volume of the microwells. After five aspiration-dispensation cycles, almost all the cells in the microwells were detached (Figure 5a,b), thus cell suspension could be stored in the microfluidic channel and tubing after the final aspiration of $100 \%$ volume of the microwells. Then we moved the microfluidic chip toward the target wells and dispensed the cell suspension. Typically we divided cells from one original microwell into two new microwells and dispensed an additional $175 \mathrm{~nL}$ medium per well to maintain the volume at $350 \mathrm{~nL}$. On average, there were about 600 cells in each original well, and after the whole procedure more than $60 \%$ of them would be recovered. Transferring only a small portion of cells from one well to another is also feasible by reducing trypsin incubation time and pipet cycles. The cells left in the original microwell could also be cultured by fresh medium dispensed immediately after the aspiration. To test the viability of the cells transferred to the new wells, we further cultured the cells for $22 \mathrm{~h}$ with medium changed every $8 \mathrm{~h}$. Cells exhibited healthy morphology and proliferated normally, indicating the success of the cell passaging.

Transfection. Transfection is another popular cell manipulation method. We transfected plasmid into the cells through the widely used lipofection method with our liquid handling system. After the cells were seeded and cultured for $12 \mathrm{~h}$, a mix of plasmid DNA and lipofectamine 2000, a liposome-based transfection reagent, were introduced into the microwells by medium change. After $5 \mathrm{~h}$ incubation, we replaced the medium with DMEM total medium supplemented with $10 \%$ FBS. After additional culture for $20 \mathrm{~h}$ with fresh medium changed every 8 $\mathrm{h}$, bright field and fluorescent microscopic images were taken (Figure 5) to assess the efficiency of transfection. We used the same transfection mix for both conventional and the chip-based approaches. To avoid evaporation during the long-time cell culture, we had to add $360 \mu \mathrm{L}$ to each container in the 12-well plate, while only $350 \mathrm{~nL}$ was needed for each microwell onchip. This over 1000-fold volume reduction also resulted in the reduced plasmid/cell ratio, from $2.0 \mathrm{pg} /$ cell (12-well plate) to $0.8 \mathrm{pg} /$ cell (microwell chip). With this reduced plasmid/cell ratio, the GFP plasmid transfection efficiency in microwells can still reach $13 \%$, which is comparable to $16 \%$ achieved in conventional approaches (Figure S6 in the Supporting Information). We also observed that the transfection efficiency and cell viability varied as the transfection reagent formula changed, as shown in Figure S7 in the Supporting Information.

Drug Induced Cell Apoptosis. We use this new platform to perform the apoptosis rate analysis of U2-OS cells. Apoptosis was induced by cisplatin, a commonly used cancer drug, for 16 h. The apoptotic cells were identified by Annexin V-FITC and PI labeling. The Annexin V-FITC positive and PI negative cells were in early apoptosis, while both Annexin V-FITC and PI positive cells were in the final stage of apoptosis. ${ }^{41}$ We noticed that some cells were taken away during liquid replacement. We believe these cells were loosely attached and belonged to the final stage of apoptosis. We counted both the missing cells and the PI positive cells and divided by the total cell number to obtain the ratio of final stage apoptosis. As shown in Figure 6,

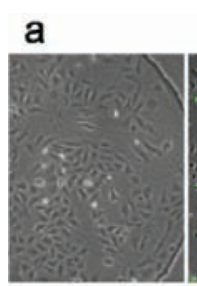

C
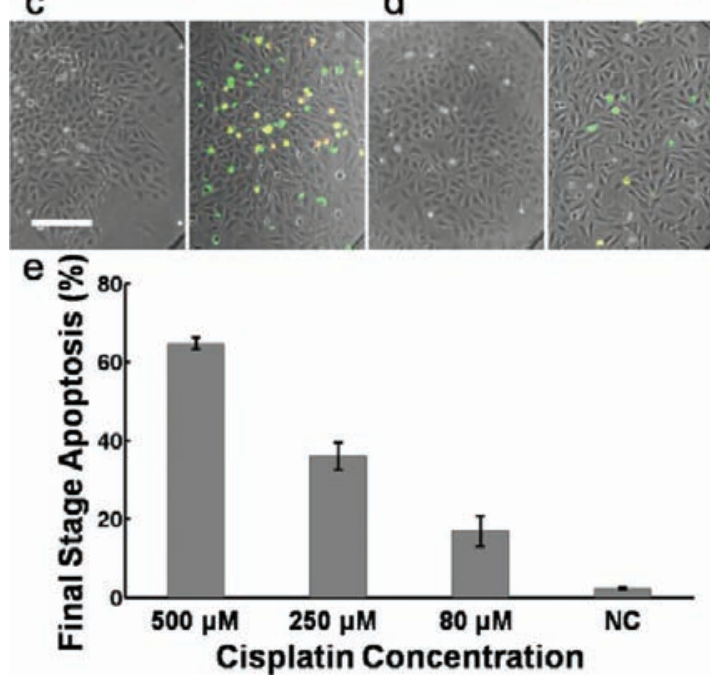

Figure 6. Cisplatin induced cell apoptosis. The phase contrast (left image of each panel) before adding cisplatin and fluorescence (merged with phase contrast image after cisplatin stimulation) microscopic images of U2-OS cells induced by (a) $500 \mu \mathrm{M}$, (b) $250 \mu \mathrm{M}$, (c) $80 \mu \mathrm{M}$, and (d) $0 \mu \mathrm{M}$ cisplatin, and the ratio of the final stage apoptotic cells under each condition is shown in part e. Annexin V-FITC (green) and PI (red) are stained after $16 \mathrm{~h}$ of drug treatment. Some cells at the final stage of apoptosis are taken away during liquid replacement. Scale bar is $0.2 \mathrm{~mm}$.

when the drug concentration was high $(500 \mu \mathrm{M})$, over $65 \%$ cells were induced to apoptosis, and over $75 \%$ of the apoptotic cells were in the final stage; while treated with lower drug concentration, a much less numbers of cells were induced to apoptosis and most of which were in the early stage. The whole experiment is automatically performed in 40 microwells on a microwell chip, with merely $0.42 \mu \mathrm{L}$ of drug stock solution in total. Compared to the conventional approach that easily cost $33.3 \mu \mathrm{L}$ of solution to reach similar throughput using a 96 well 
plate, this 80 -fold reduction of reagent consuming, together with robust and accurate liquid handling, will greatly facilitate the cell-based high-throughput and high-content screenings.

\section{CONCLUSIONS}

We have developed a high-throughput, openly accessible, and highly automated liquid handling system to culture cells within the nanoliter range through a microfluidic approach. The cells were cultured on a chip containing $12 \times 8$ individual open microwells with single well addressability. Each microwell could hold a maximum of $500 \mathrm{~nL}$ of medium containing 50 to more than 1000 cells. The complete cell culture procedure and a few key cell manipulation experiments, including cell passage and plasmid transfection, were automatically performed on the chip. Besides, we evaluated drug-induced apoptosis on U2-OS cells in a parallel manner. The system was able to deliver and change soluble reagents to arbitrary microwells. Combined with a microscope, this system can perform fully automatic cell culture, manipulation, and real-time observation. After handling one well, the microfluidic pipet chip can be cleaned before it reaches another well to prevent cross contamination. Our method requires much less consumption of samples and reagents, provides largescale uniformity and reproducibility, and offers great flexibility to handle multiple tasks with a single set of devices. This nanoliter cell culture system can also be easily coupled with other technologies to facilitate the high-throughput studies on cell arrays. Moreover, both the microwell chip and microfludic chip can be scaled down to fit high-throughput single-cell-based manipulation and analysis such as stem cell culture and hybridoma screening. We envision that this system could be well adapted to numerous applications for cell assays.

\section{ASSOCIATED CONTENT}

\section{S Supporting Information}

Additional information as noted in text. This material is available free of charge via the Internet at http://pubs.acs.org.

\section{AUTHOR INFORMATION}

\section{Corresponding Author}

*E-mail: yanyi@pku.edu.cn.

\section{Notes}

The authors declare no competing financial interest.

\section{ACKNOWLEDGMENTS}

The authors thank Chunhong Zheng for the help on the cell culture, Liang Zhao for the help on cell staining, Zhilong Yu for the help on confocal microscopy, and Zitian Chen for the help on the illustration drawing. This work is supported by the National Natural Science Foundation of China (Grants 90913011 and 20905004), the Ministry of Science and Technology of China (Grants 2009AA04Z309 and 2011CB809106), Beijing Natural Science Foundation (Grant 2082011), and the Fok Ying Tong Education Foundation.

\section{REFERENCES}

(1) Inglese, J.; Johnson, R. L.; Simeonov, A.; Xia, M.; Zheng, W.; Austin, C. P.; Auld, D. S. Nat. Chem. Biol. 2007, 3 (8), 466-479.

(2) Dittrich, P. S.; Manz, A. Nat. Rev. Drug Discovery 2006, 5 (3), 210-218.

(3) Neumann, B.; Walter, T.; Heriche, J. K.; Bulkescher, J.; Erfle, H.; Conrad, C.; Rogers, P.; Poser, I.; Held, M.; Liebel, U.; Cetin, C.; Sieckmann, F.; Pau, G.; Kabbe, R.; Wunsche, A.; Satagopam, V.; Schmitz, M. H.; Chapuis, C.; Gerlich, D. W.; Schneider, R.; Eils, R.;
Huber, W.; Peters, J. M.; Hyman, A. A.; Durbin, R.; Pepperkok, R.; Ellenberg, J. Nature 2010, 464 (7289), 721-727.

(4) Wang, J.; Zhou, Y.; Qiu, H.; Huang, H.; Sun, C.; Xi, J.; Huang, Y. Lab Chip 2009, 9 (13), 1831-5.

(5) Upadhyaya, S.; Selvaganapathy, P. R. Lab Chip 2010, 10 (3), 341-348.

(6) Young, D. W.; Bender, A.; Hoyt, J.; McWhinnie, E.; Chirn, G. W.; Tao, C. Y.; Tallarico, J. A.; Labow, M.; Jenkins, J. L.; Mitchison, T. J.; Feng, Y. Nat. Chem. Biol. 2008, 4 (1), 59-68.

(7) Sundberg, S. A. Curr. Opin. Biotechnol. 2000, 11 (1), 47-53.

(8) Diaz-Mochon, J. J.; Tourniaire, G.; Bradley, M. Chem. Soc. Rev. 2007, 36 (3), 449-457.

(9) Erfle, H.; Neumann, B.; Liebel, U.; Rogers, P.; Held, M.; Walter, T.; Ellenberg, J.; Pepperkok, R. Nat. Protoc. 2007, 2 (2), 392-399.

(10) Thorsen, T.; Maerkl, S. J.; Quake, S. R. Science 2002, 298 (5593), 580-584.

(11) Ochsner, M.; Dusseiller, M. R.; Grandin, H. M.; Luna-Morris, S.; Textor, M.; Vogel, V.; Smith, M. L. Lab Chip 2007, 7 (8), 10741077.

(12) Song, Q.; Han, Q.; Bradshaw, E. M.; Kent, S. C.; Raddassi, K.; Nilsson, B.; Nepom, G. T.; Hafler, D. A.; Love, J. C. Anal. Chem. 2010, 82 (2), 473-477.

(13) Charnley, M.; Textor, M.; Khademhosseini, A.; Lutolf, M. P. Integr. Biol. 2009, 1 (11-12), 625-634.

(14) Di Carlo, D.; Wu, L. Y.; Lee, L. P. Lab Chip 2006, 6 (11), $1445-1449$

(15) Khademhosseini, A.; Yeh, J.; Eng, G.; Karp, J.; Kaji, H.; Borenstein, J.; Farokhzad, O. C.; Langer, R. Lab Chip 2005, 5 (12), $1380-1386$.

(16) Wang, Z. H.; Kim, M. C.; Marquez, M.; Thorsen, T. Lab Chip 2007, 7 (6), 740-745.

(17) Gomez-Sjoberg, R.; Leyrat, A. A.; Pirone, D. M.; Chen, C. S.; Quake, S. R. Anal. Chem. 2007, 79 (22), 8557-8563.

(18) Oh, K. W.; Park, C.; Namkoong, K.; Kim, J.; Ock, K. S.; Kim, S.; Kim, Y. A.; Cho, Y. K.; Ko, C. Lab Chip 2005, 5 (8), 845-850.

(19) Liu, J.; Hansen, C.; Quake, S. R. Anal. Chem. 2003, 75 (18), $4718-4723$.

(20) Wang, H.; Liu, K.; Chen, K. J.; Lu, Y.; Wang, S.; Lin, W. Y.; Guo, F.; Kamei, K.; Chen, Y. C.; Ohashi, M.; Wang, M.; Garcia, M. A.; Zhao, X. Z.; Shen, C. K.; Tseng, H. R. ACS Nano 2010, 4 (10), 62356243.

(21) Fink, J.; Thery, M.; Azioune, A.; Dupont, R; Chatelain, F.; Bornens, M.; Piel, M. Lab Chip 2007, 7 (6), 672-680.

(22) Cheng, X. H.; Wang, Y. B.; Hanein, Y.; Bohringer, K. F.; Ratner, B. D. J. Biomed. Mater. Res., Part A 2004, 70A (2), 159-168.

(23) Love, J. C.; Ronan, J. L.; Grotenbreg, G. M.; van der Veen, A. G.; Ploegh, H. L. Nat. Biotechnol. 2006, 24 (6), 703-707.

(24) Barbulovic-Nad, I.; Au, S. H.; Wheeler, A. R. Lab Chip 2010, 10 (12), 1536-1542.

(25) Liberski, A. R.; Delaney, J. T. Jr.; Schubert, U. S. ACS Comb. Sci. 2011, 13 (2), 190-195.

(26) Unger, M. A.; Chou, H. P.; Thorsen, T.; Scherer, A.; Quake, S. R. Science 2000, 288 (5463), 113-116.

(27) Berthier, E.; Warrick, J.; Yu, H.; Beebe, D. J. Lab Chip 2008, 8 (6), 852-859.

(28) Abramoff, M. D.; Magalhaes, P. J.; Ram, S. J. Biophoton. Int. 2004, 11 (7), 36-42.

(29) Chang-Yen, D. A.; Gale, B. K. Eng. Med. Biol. Soc. Ann. 2005, $31-33$.

(30) Chang-Yen, D. A.; Myszka, D.; Gale, B. K. Proc. SPIE 2005, 5718, 110-120.

(31) Chen, D.; Du, W. B.; Liu, Y.; Liu, W. S.; Kuznetsov, A.; Mendez, F. E.; Philipson, L. H.; Ismagilov, R. F. Proc. Natl. Acad. Sci. U.S.A. 2008, 105 (44), 16843-16848.

(32) Liu, Y.; Ismagilov, R. F. Langmuir 2009, 25 (5), 2854-9.

(33) Ainla, A.; Jansson, E. T.; Stepanyants, N.; Orwar, O.; Jesorka, A. Anal. Chem. 2010, 82 (11), 4529-36.

(34) Kang, L. F.; Hancock, M. J.; Brigham, M. D.; Khademhosseini, A. J. Biomed. Mater. Res., Part A 2010, 93A (2), 547-557. 
(35) Ferrell, N.; Gallego-Perez, D.; Higuita-Castro, N.; Butler, R. T.; Reen, R. K.; Gooch, K. J.; Hansford, D. J. Anal. Chem. 2010, 82 (6), $2380-2386$.

(36) Rettig, J. R.; Folch, A. Anal. Chem. 2005, 77 (17), 5628-5634.

(37) Merrin, J.; Leibler, S.; Chuang, J. PLoS One 2007, 2 (7).

(38) Yamazoe, H.; Tanabe, T. J. Biomed. Mater. Res., Part A 2009, $91 A$ (4), 1202-1209.

(39) Demirci, U.; Montesano, G. Lab Chip 2007, 7 (9), 1139-1145. (40) Nakamura, M.; Kobayashi, A.; Takagi, F.; Watanabe, A.; Hiruma, Y.; Ohuchi, K.; Iwasaki, Y.; Horie, M.; Morita, I.; Takatani, S. Tissue Eng. 2005, 11 (11-12), 1658-1666.

(41) Zimmermann, K. C.; Ricci, J. E.; Droin, N. M.; Green, D. R J. Cell Biol. 2002, 156 (6), 1077-1087. 


\title{
Supporting Information
}

\section{Openly Accessible Microfluidic Liquid Handlers for}

\section{Automated High-throughput Nanoliter Cell Culture}

\author{
Ying Zhou, Yuhong Pang, and Yanyi Huang*
}

College of Engineering, and Biodynamic Optical Imaging Center (BIOPIC),

Peking University, Beijing 100871, China

E-mail: yanyi@pku.edu.cn

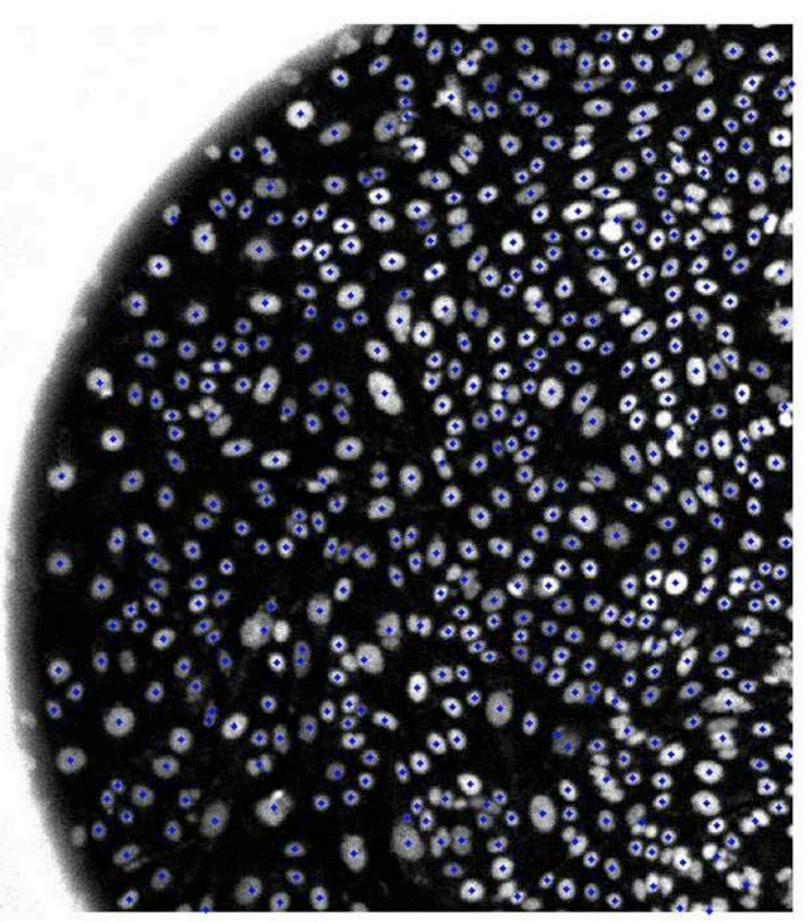

Figure S1. Cell counting with a confocal microscopic image. The cell number was 464 and 476, counted automatically by a home-developed image processing program and manually with Image J, respectively. White spots were nuclei stained by Hoechst 33342. Blue spots indicated the centroids of cells recognized automatically. Most mis-counting was caused by the connected cell nuclei. 

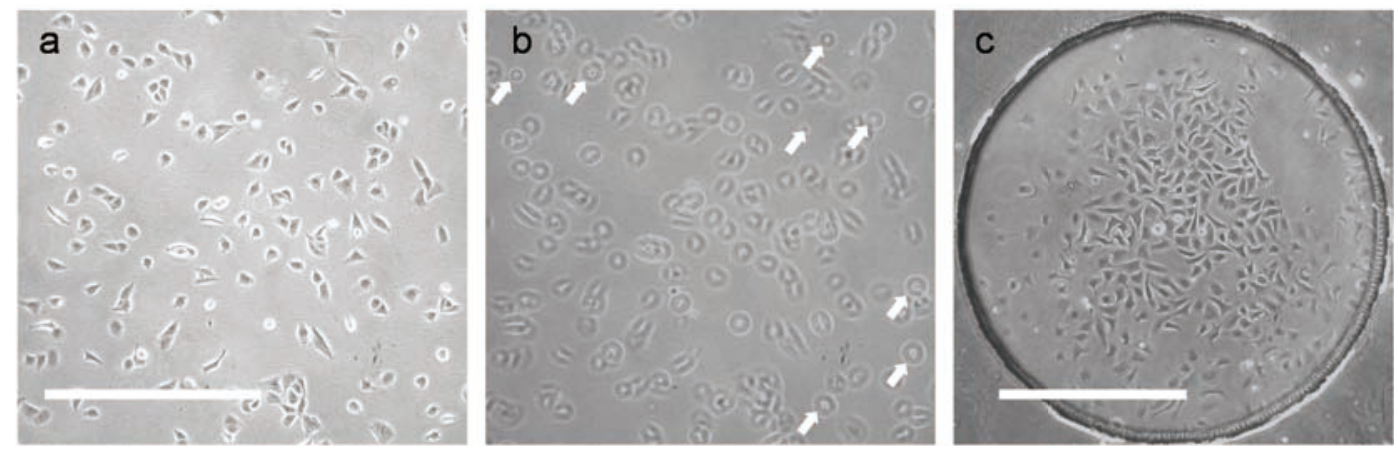

Figure S2. Evaluation of the cell damage caused by dispensation by comparing the number of cells suspended and the number of cells adhered at the 6 th $\mathrm{h}$ after cell seeding. Images of cells cultured in the flask, focusing on the attached cells (a) and suspended cells (b). White arrows in (b) indicate suspending cells. In this field of view, the ratio of suspended cells to the attached cells is $4.8 \%$ (8/166). (c) The image of cell cultured in a microwell. The suspended/attached ratio is $5.2 \%(14 / 270)$. Scale bars are $0.5 \mathrm{~mm}$.

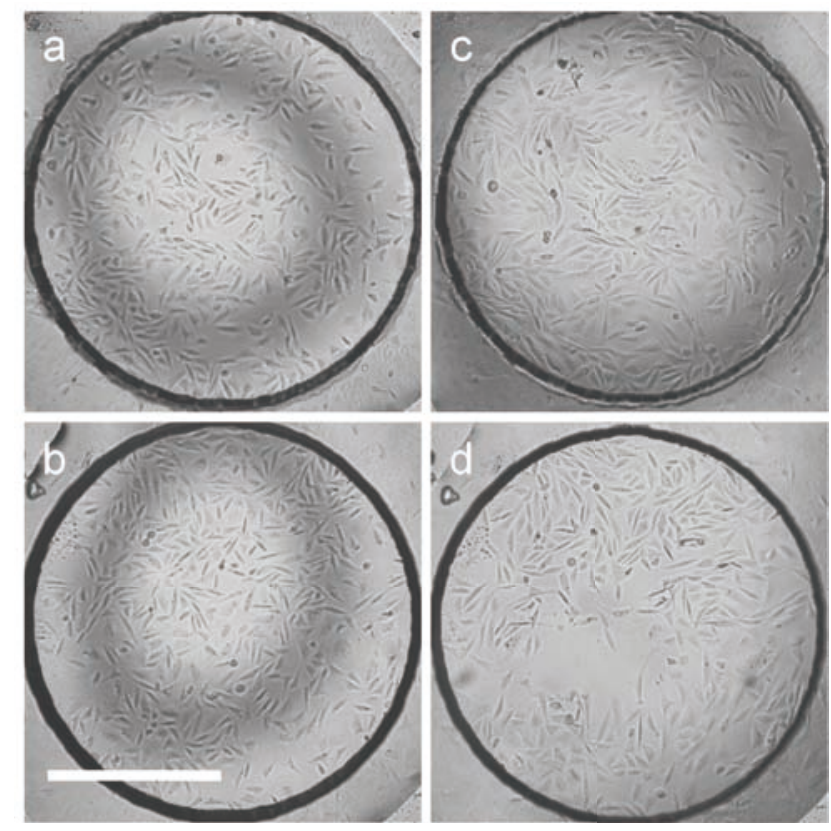

Figure S3 (a) Before and (b) after 8 medium change cycles with $90 \%$ liquid replaced per cycle. Few cells were detached. (c) Before and (d) after 8 medium change cycles with more than $98 \%$ liquid replaced per cycle. The distance between the nozzle tip and the bottom of the well was smaller than $5 \mu \mathrm{m}$ in this case. Some cells close to the nozzle region were detached probably because the nozzles mechanically scratched them away. Scale bar is $0.5 \mathrm{~mm}$. 


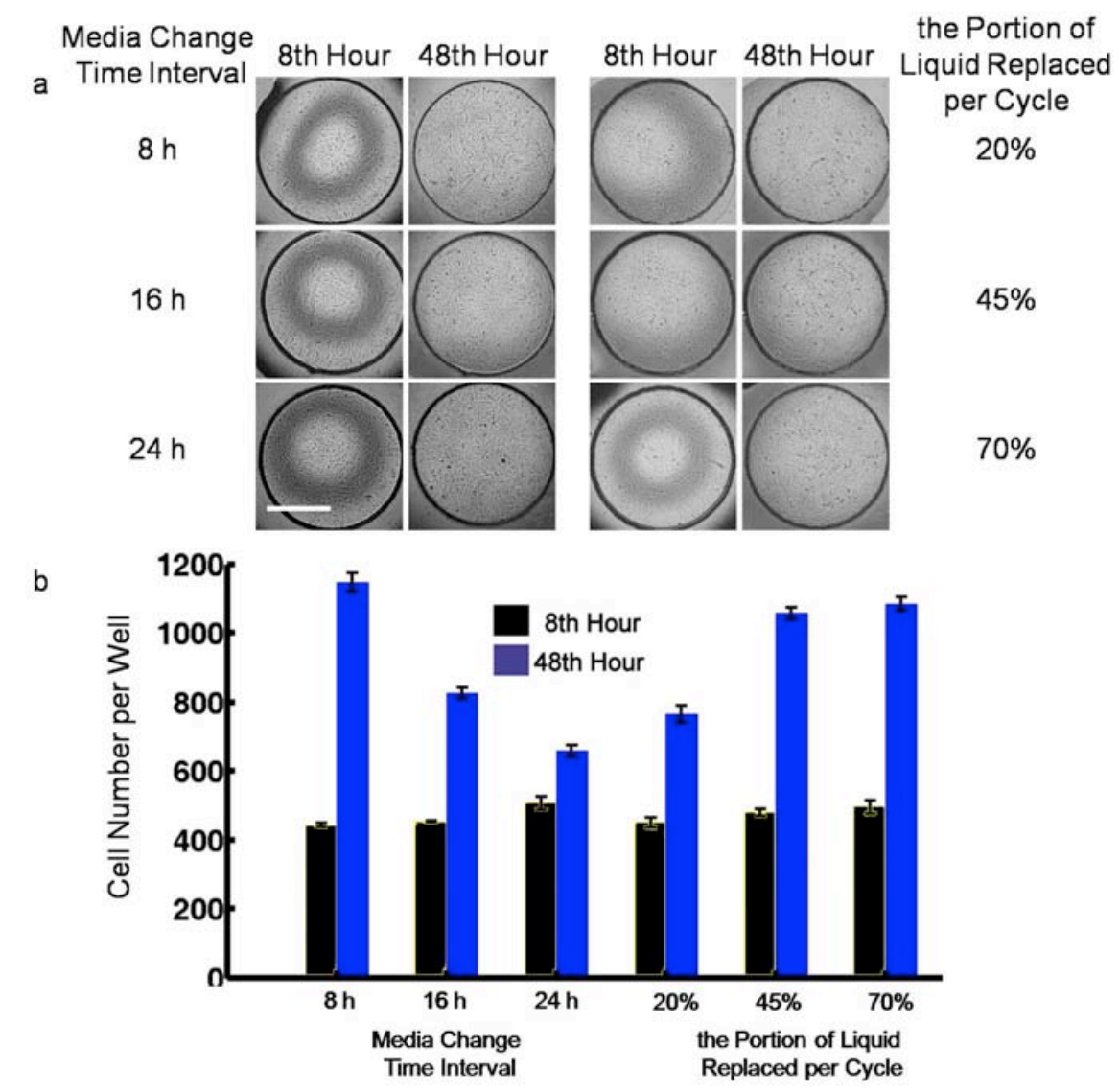

Figure S4. Investigation of the effect of different medium change time interval and the portion of liquid replaced per cycle to longtime cell culture. (a) Left panel: cells were cultured for $48 \mathrm{~h}$ with medium changed every 8 h, 16 h, and 24 h, respectively. $45 \%$ of the liquid of a well was replaced per cycle. Right panel: cells were cultured for $48 \mathrm{~h}$ with $20 \%, 45 \%$, and $70 \%$ of the liquid of a well replaced per cycle. The medium was changed each $8 \mathrm{~h}$. Scale bar is $0.5 \mathrm{~mm}$. (b) Cell numbers at the 8th and 48th hour were counted. Although the proliferation rates obtained from different batches of experiments were slightly different depending on the cell status (for example, left panel vs. right panel), the repeatability between wells was great in the same batch of experiments.

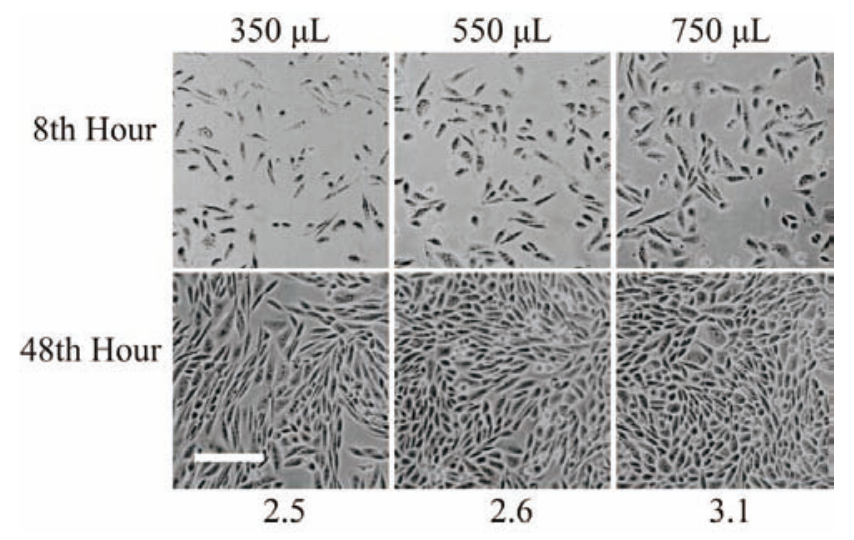

Figure S5. Proliferation rates of $\mathrm{CHO}$ cells cultured in the 12-well plates. The culture volume of each well is set to be $350 \mu \mathrm{L}, 550 \mu \mathrm{L}$, or $750 \mu \mathrm{L}$, respectively. The corresponding increase of the cell number is $2.5,2.6$, and 3.1. Scale bar is $0.2 \mathrm{~mm}$. 

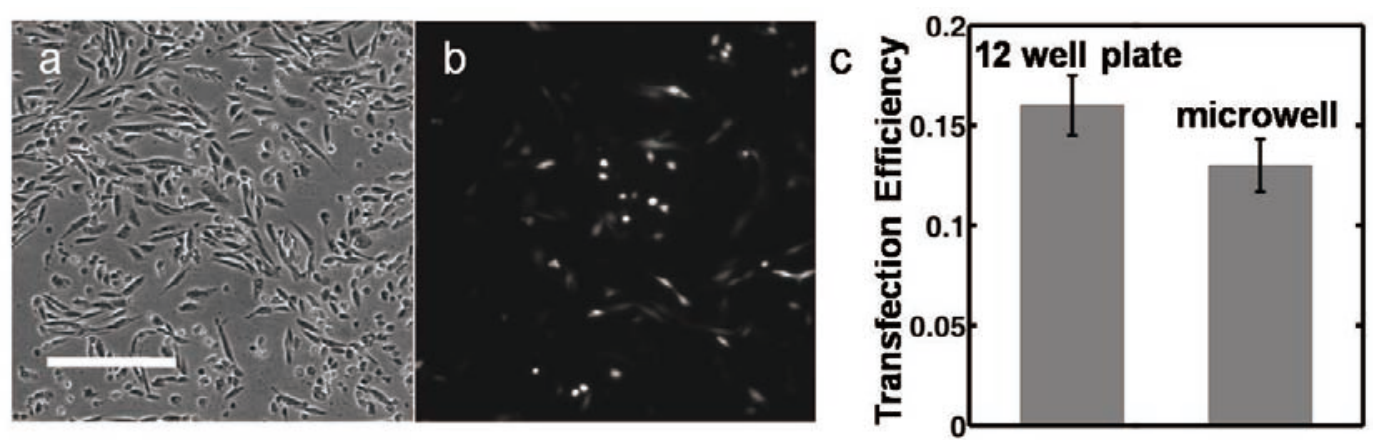

Figure S6. The GFP plasmid transfection in 12-well plates. (a) Bright field and (b) fluorescent images show that $16 \%$ cells in the well expressed GFP $20 \mathrm{~h}$ after the transfection. Scale bar is 0.2 $\mathrm{mm}$. (c) Transfection in microwells on-chip has comparable efficiency (13\%).
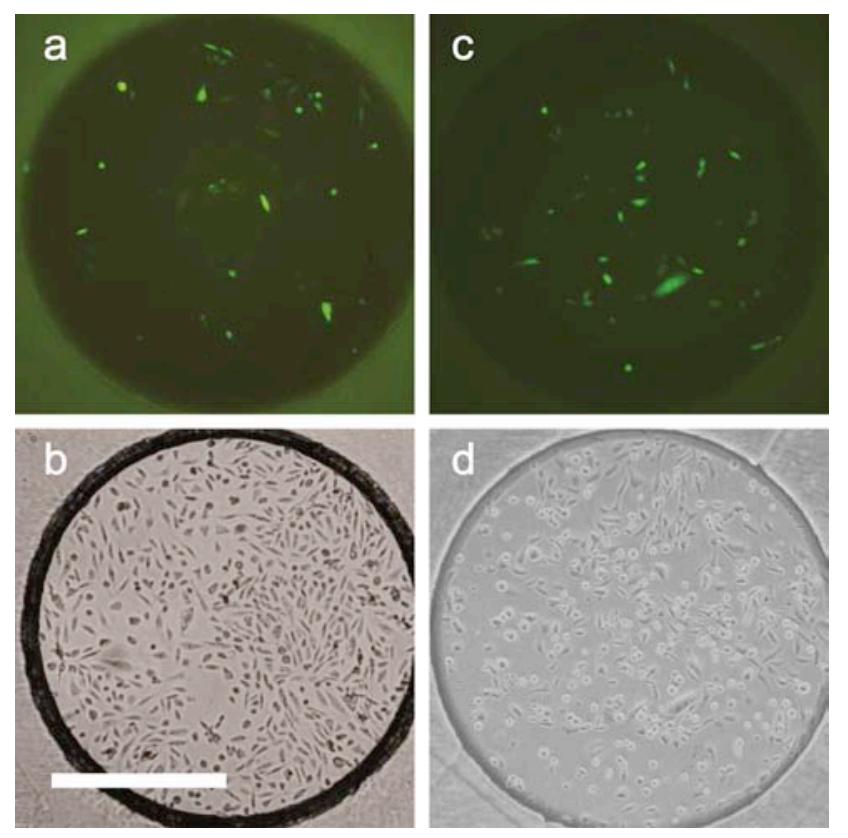

Figure S7. Fluorescent (a) and (c) and corresponding phase contrast (b) and (d) images were taken $20 \mathrm{~h}$ after the transfection of GFP plasmid DNA on the microwell chips. For (a) and (b), the formula of the transfection mix was the same as that in conventional experiments. For (c) and (d): the amount of lipofectamine was 3 times as much as that in (a) and (b). The additional amount of lipofectamine 2000 increased transfection efficiency but decreased cell viability. Scale bar is 0.5 $\mathrm{mm}$. 


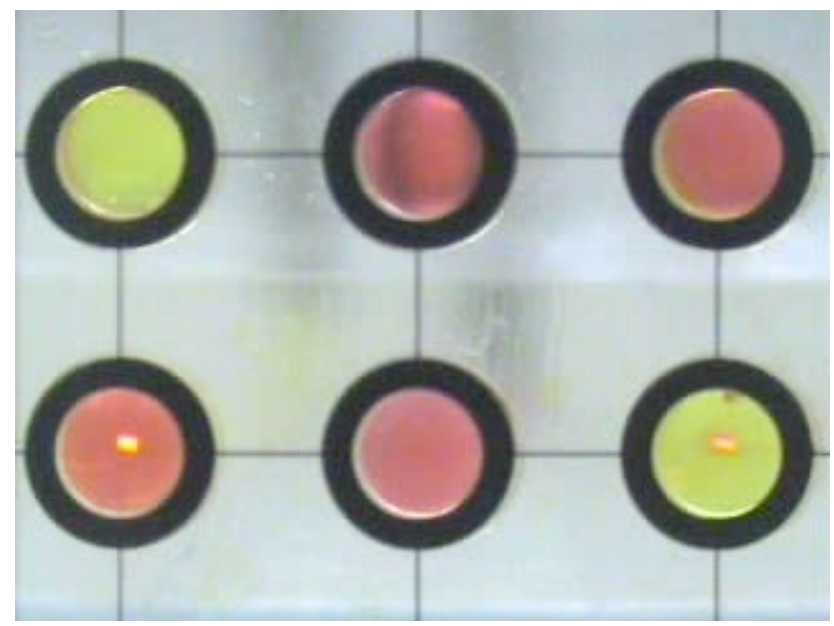

Movie S1 Demonstration of the dispensation and replacement procedures by dyes (bottom view).

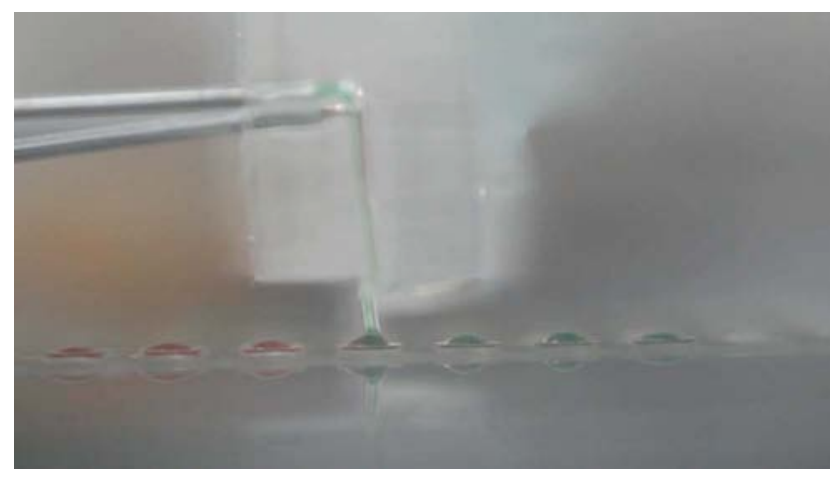

Movie S2 Dispense red dye, and then replace red dye by green dye (side view). $45 \%$ of the liquid in the well was replaced each cycle.

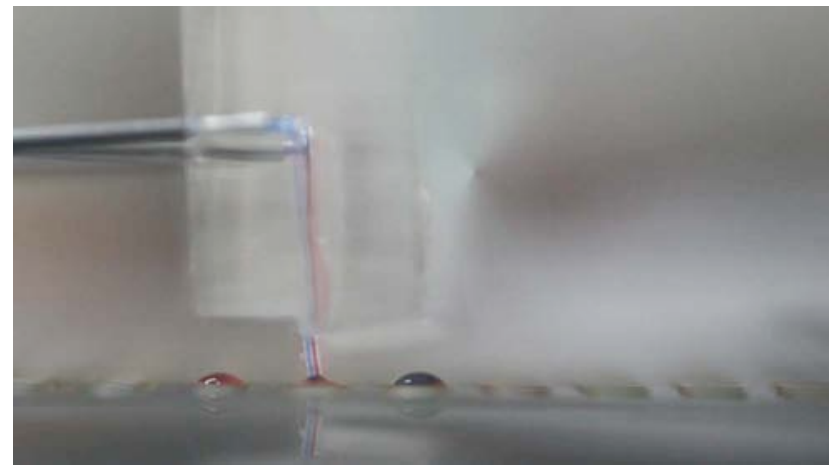

Movie S3 Dispense red dye, and then replace red dye by blue dye (side view). 20\%, 45\%, and 70\% of the liquid in the well was replaced per cycle for the 3 microwells (from right to left), respectively. 